\title{
RELIGIOSIDADE E IDEAÇÃO SUICIDA EM JOVENS CRISTÃOS
}

RELIGIOUSITY AND SUICIDE IDEA IN YOUTH CRISTHIANS

Ramonielson Medeiros da Silva ${ }^{87}$ 


\section{RESUMO}

suicídio é um fenômeno multidimensional, considerado como um grave problema de saúde pública a nível global, devendo ser entendido a partir de uma abordagem ecológica. Este estudo tem como objetivo analisar se a religiosidade pode ser fator de proteção contra a ideação suicida em jovens cristãos. Para tanto, realizou-se uma pesquisa de campo, de natureza quantitativa e cunho descritivo, com uma amostra não-probabilística acidental, com total de 50 participantes, maiores de 18 anos, de ambos os sexos. Na coleta de dados foram utilizados três instrumentos: um questionário sócio-demográfico, a Escala de Religiosidade Durel e a Escala Multi-Atitudinal de Tendência ao Suicídio, que foram analisados através de estatísticas descritivas e inferenciais. Observou-se que a amostra possui elevado grau de envolvimento religioso, com alta frequência a reuniões, práticas religiosas e percepção subjetiva do divino, principalmente, entre evangélicos e participantes do sexo masculino. A análise correlacional apresentou associações significativas entre o fator atração pela morte e as dimensões de religiosidade organizacional, nãoorganizacional e intrínseca, o que sugere que a relação do sujeito com suas crenças religiosas tem um papel importante quanto à atração pela morte, sendo necessários mais estudos, visando especificar quais crenças religiosas atuam de maneira protetiva contra a ideação suicida.

\section{PALAVRAS-CHAVE}

Suicídio. Religiosidade. Ideação Suicida.

\section{ABSTRACT}

Suicide is a multidimensional phenomenon considered as a serious global public health problem and should be understood from an ecological approach. This study aims to analyze whether religiosity can be a protective factor against suicidal ideation in young Christians. To this end, a quantitative and descriptive field research was conducted with an accidental non-probabilistic sample, with a total of 50 participants, over 18 years old, of both sexes. Three instruments were used to collect data: a socio-demographic questionnaire, the Durel Religiousness Scale and the Suicide 
Tendency Multi-Attitudinal Scale, which were analyzed using descriptive and inferential statistics. It was observed that the sample has a high degree of religious involvement, with high frequency of meetings, religious practices and subjective perception of the divine, especially among evangelicals and male participants. The correlational analysis showed significant associations between the attraction to death factor and the dimensions of organizational, non-organizational and intrinsic religiosity, suggesting that the subject's relationship with his or her religious beliefs plays an important role in the attraction to death, requiring more studies to specify which religious beliefs act in a protective manner against suicidal ideation.

\section{KEYWORDS}

Suicide. Religiosity. Suicide Idea.

\section{INTRODUÇÃO}

Mesmo com o passar do tempo, o problema do suicídio continua um desafio para a comunidade global. As estatísticas referentes à mortalidade por suicídio são alarmantes. Conforme dados da Organização Mundial de Saúde (WHO, 2018), cerca de 800 mil pessoas tiram suas vidas por ano no mundo, sendo esta a segunda maior causa de morte entre jovens com idades entre 15 e 29 anos. É válido ressaltar ainda que estes números podem ser ainda maiores, devido a vários fatores: subnotificação de casos, registros de óbito com uma causa ambígua ou até mesmo a dificuldade que há em se definir se um acidente de trânsito foi uma fatalidade ou uma tentativa de suicídio (BRAGA; DELL' AGLIO, 2013).

No Brasil, entre os anos 2007 a 2016, houveram 106.374 registros de óbitos, tendo como causa suicídio no Sistema de Informações Sobre Mortalidade (BRASIL, 2018). É importante destacar ainda que, muito embora a taxa de mortalidade por suicídio entre brasileiros seja menor que a global - estimada em 10,5/100 mil habitantes - ao se considerar o período 2007-2016, houve crescimento de $18 \%$ na taxa de suicídios, partindo de 4,9/100 mil habitantes em 2007 para 5,8/100 mil habitantes em 2016, o que mostra que o problema vem aumentando ultimamente, no contexto brasileiro (WHO, 2018). 
Nesta perspectiva, emerge a necessidade de se aprofundar no conhecimento dos possíveis fatores de prevenção a ocorrência de um comportamento suicida, com destaque para a religiosidade, característica tão marcante da cultura brasileira e, que segundo Botega (2015) tem um alto potencial preventivo, não importando qual seja a filiação religiosa.

No tocante aos riscos, há que se ressaltar os desafios que enfrentam a camada jovem da população, como: as diversas pressões sociais e acadêmicas, o ingresso no mercado de trabalho cada vez mais competitivo, a busca por relacionamentos íntimos, entre outros. Tais fatores podem ser elementos altamente estressores, desencadeando, por vezes em ideação suicida (RIBEIRO; MOREIRA, 2018).

\subsection{REVISÃO SÓCIO-HISTÓRICA DO SUICÍDIO}

Etimologicamente, a palavra suicídio tem origem latina, sendo composta pelos termos sui (a si mesmo) e caederes (ação de matar) e seus primeiros usos datam por volta do século XII da era comum (BOTEGA, 2015).

Importa destacar também que há muitas visões a respeito

do ato suicida que têm sido construídas ao longo da história humana. Como salientam Mostafazadeh-Bora e Zarghami (2016), os fatores culturais dos países têm forte influência na visão das pessoas sobre o suicídio. Para eles, os orientais, de modo geral, o encaram como um ato de nobreza e auto-sacrifício, enquanto que os ocidentais o percebem como fraqueza moral.

No entanto, buscando ir além do senso-comum, o sociólogo Émile Durkheim, em um dos primeiros estudos de cunho científico sobre a temática do suicídio, tratou de defini-lo operacionalmente como sendo: “... todo caso de morte que resulta direta ou indiretamente de um ato positivo ou negativo praticado pela própria vítima, ato que a vítima sabia dever produzir este resultado" (DURKHEIM, 2000, p. 15).

Em sua análise sociológica, Durkheim (2000) procurou descobrir quais as causas que levam uma pessoa a tirar sua vida e subdividiu o suicídio em três categorias: egoísta, altruísta e anômico. O tipo egoísta é aquele em que o sujeito, por razões individualistas tira sua própria vida. Esta categoria é típica das sociedades modernas, onde, por vezes, o indivíduo não se 
encontra integrado a algum grupo social, como família, amigos, grupos comunitários.

Já o tipo altruísta ocorre quando a pessoa, por causa de pressões externas, de honra, moralidade ou mesmo em obediência a alguma norma social, comete suicídio. Ao contrário do egoísta, este ocorre com maior frequência em sociedades menos industrializadas e com maior coesão social. O terceiro tipo, o anômico, é caracterizado por estar relacionado a algum tipo de crise social, política ou econômica, que por sua vez altera a estrutura de vida da pessoa, que não consegue lidar com as mudanças e exigências desse novo modelo que lhe imposto e, com isso, tira sua própria vida.

Atualmente, boa parte dos estudiosos dividem o espectro do comportamento suicida em três fases, que se estruturam em uma espécie de continuum, que perpassa: a ideação suicida, planejamento suicida, a tentativa de suicídio e, por fim, o suicídio consumado (ASANTE, 2017).

A ideação suicida corresponde a pensamentos e fantasias sobre suicidar-se, sendo esta fase, segundo Raynolds (1991) apud Freitas (2011), uma importante variável preditiva sobre a possibilidade de efetivação do suicídio. Já no que diz respeito à etapa do planejamento, Silverman et. al (2007) apud Asante (2017) afirmam que esta consiste em escolher e traçar um esboço específico da forma como intenta tirar a vida.

A tentativa de suicídio pode ser entendida como qualquer comportamento suicida auto-infligido, que não tenha resultados fatais (WHO, 2014). Estima-se que haja mais de vinte tentativas para cada suicídio consumado, o que configura a etapa da tentativa a principal indicadora de efetivação do suicídio no futuro (WHO, 2018; BOTEGA, 2014).

Esta divisão do comportamento suicida em fases pode conduzir-nos a enxergar o suicídio como um ato exclusivamente individual. No entanto, como sugere Santos (2018), há que se encarar este fenômeno a partir de uma perspectiva ecológica, isto é, levando-se em consideração fatores biopsicossociais, econômicos, políticos, religiosos, dentre outros.

A perspectiva ecológica é importante não apenas para se compreender o fenômeno, como também para propor medidas de prevenção. De fato, intervenções individualizadas tem o seu valor no sentido de adiar um comportamento suicida específico, de maneira pontual. Entretanto, ao se adotar uma abordagem ecológica, isto é, centrada em promover a saúde mental na 
comunidade, de maneira integral, não apenas eliminando os fatores de risco, mas fortalecendo fatores protetivos, os resultados positivos, certamente, serão maximizados.

\subsection{A INTERFACE ENTRE RELIGIOSIDADE E SUICÍDIO}

Em seu estudo clássico sobre suicídio, Durkheim (2000) já chamava atenção para o fato de que pessoas com alto nível de envolvimento religioso terem menores chances de cometer suicídio, devido ao alto nível de integração social que a religião promove. Muito embora, suas análises estatísticas mostrarem que, mesmo que o cristianismo, em suas variações denominacionais, condene moralmente $o$ ato de tirar a própria vida, havia entre os países protestantes um índice de mortalidade por suicídio.

Apesar de antiga, a hipótese durkhemiana tem sido confirmada por outros pesquisadores como Becker e Woessmann (2011), cujos dados mostraram que países de maioria protestante tendem a ter taxas de suicídio mais altas que de maioria católica. Para estes autores, a diferença entre as taxas tem relação com as diferenças doutrinárias entre as diversas ramificações cristãs, como, por exemplo, o entendimento da graça de Deus e a possibilidade de confissão de pecados, rito este inexistente entre as igrejas protestantes.

Entretanto, é necessário assinalar que, de acordo com Jongkind et. al (2018), há na literatura especializada sobre suicídio evidências que sugerem que o envolvimento religioso é um fator de proteção contra o suicídio, bem como, há outros estudos que mostram que alguns aspectos específicos das diversas religiões não funcionam necessariamente como proteção ao comportamento suicida.

Em um estudo recente, Kralovec et. al (2017), averiguaram que os benefícios protetivos da religião com relação ao suicídio estão ligados ao modo como a pessoa se relaciona com suas crenças religiosas, se há atendimento na igreja, qual o nível de envolvimento nas práticas públicas da religião e as possíveis objeções morais ao suicídio. Outro importante dado levantado por estes autores é que há um baixo nível de agressividade entre indivíduos religiosos, assim como menores índices de consumo de substâncias psicoativas, o que por sua vez, torna o suicídio menos provável entre grupos religiosos. 
Ainda vale destacar que a religiosidade se mostrou positivamente correlacionada a outras variáveis consideradas como protetivas contra o suicídio, como satisfação com a vida e bem-estar subjetivo, bem como apresentou correlação negativa com fatores de risco, como depressão, ideação suicida, em boa parte dos estudos ao longo do século XX, conforme destacam Moreira-Almeida, Lotufo Neto e Koenig (2006), em seu trabalho de revisão sistemática sobre a relação entre religiosidade e saúde mental.

Há ainda o estudo de Spencer-Thomas (2018) que mostra como as crenças e práticas de espiritualidade, aliados à participação em uma comunidade de fé, quando trabalhando em conjunto, operam no sentido de construir uma estrutura protetiva contra o suicídio, que ocorre em três níveis, que são: prevenção, intervenção e resposta a crises.

O nível da prevenção está ao ligado ao fato de que a participação em comunidades de fé pode propiciar um aumento na capacidade de resiliência do indivíduo, bem como oferecer um suporte social, capaz de conferir-lhe um sentimento de pertença e significado, como por exemplo, através do engajamento em causas sociais.

No que tange à intervenção, a autora assinala que uma comunidade de fé possui um importante papel na identificação de emergências suicidas, pois seus membros, partilham de uma rede de apoio e assistência mútua, o que possibilita aos seus integrantes perceberem mudanças no comportamento uns dos outros, que possam indicar algum risco de suicídio. Já quanto a resposta a crises, o envolvimento religioso pode fornecer apoio emocional em situações de desastres, tragédias e dificuldades, ajudando na elaboração das perdas e no enfrentamento das demandas da vida, pois pode ressignificar o sofrimento vivenciado.

No entanto, de acordo com um estudo de Ning Hsieh (2017), realizado em 42 nações, distribuídas em 7 regiões geográfico culturais, os benefícios protetivos da participação religiosa em relação ao suicídio podem estar sujeitos à variação regional. Os dados apontaram que em países anglófonos, latinoamericanos, bem como o leste e norte europeu, o envolvimento religioso apresentou-se um fator de proteção contra o suicídio, enquanto em nações localizadas no oeste asiático, no sul e oeste europeu, tal envolvimento mostrou-se como elevadora do risco. Para ele, as variações são proporcionais ao grau de 
integração/regulação das comunidades religiosas, bem como de fatores como subnotificação de casos de suicídio.

\subsection{SUICÍDIO E GÊNERO}

A relação entre suicídio e gênero vem sendo estudada desde o século XIX, como é o caso de Émile Durkheim (2000), que nesta época já observou que as altas taxas de mortalidade por comportamento suicida entre homens eram 4 vezes maiores que entre mulheres, o que lhe fez pensar que este é um fenômeno "essencialmente masculino".

É interessante notar que a observação durkheimiana sobre as diferenças de gênero ainda perduram. Em um estudo sobre as taxas de mortalidade por suicídio em vários países, realizado por Chen et. al (2017), observou-se que a proporção de mortalidade por suicídio entre homens é 3 a 4 vezes maior em países ocidentais, mais de 4 vezes na Europa Oriental e próximo de 2 vezes no leste asiático.

Quanto ao contexto brasileiro, de acordo com dados do Ministério da Saúde, os homens apresentam a maior taxa de mortalidade por suicídio 9,2/100 mil habitantes, sendo esta a terceira causa de morte mais comum entre este grupo; entre mulheres a taxa de suicídio é de 2,4/100 mil habitantes, sendo a oitava causa de morte mais comum (BRASIL, 2017).

No entanto, deve-se destacar que há uma discrepância de gênero entre tentativas de suicídio e o ato propriamente dito, qual seja: mulheres têm um número maior de tentativas de suicídio, mas baixos índices de mortalidade por suicídio, enquanto que os homens possuem menores registros de tentativas de suicídio e maiores taxas de mortalidade (VASCONCELOS-RAPOSO et. al. 2016). Esta diferença não é observada apenas no Brasil, mas em outros países também, como apontam os dados obtidos em um estudo realizado por Freeman et. al (2017), que analisaram as taxas de tentativas de suicídio na Irlanda, Hungria, Alemanha e Portugal, durante os anos de 2008 a 2013, verificando que as mulheres apresentam maiores taxas de tentativa de suicídio.

Tal diferença no comportamento suicida é comumente chamada de "Paradoxo do Gênero" e várias explicações têm sido propostas para este fenômeno, sendo a mais comum o fato de que homens recorrem a métodos mais violentos para tirar suas vidas, como por exemplo, a utilização de armas de fogo e enforcamento 
(STACK, 2018). Sob uma perspectiva psicossocial, Abreu et. al. (2010) explicam que, geralmente, mulheres optam por abordagens menos letais, como o envenenamento, para que não percam seus atributos estéticos após o ato, enquanto que homens preferem meios mais letais, como o uso de arma de fogo e enforcamento, a fim de mostrarem sua virilidade.

Diante disso, há que se levar em consideração a importância que os papéis sociais associados às figuras masculinas e femininas têm na constituição da subjetividade humana, bem como entender a relação que há entre estes e a maneira como as pessoas lidam com o sofrimento, em suas diversas expressões. Nesta perspectiva, Zanello (2018) delimita como dois principais dispositivos sociais atribuídos à mulher, que são o da maternidade e o amoroso, onde é esperado que que a mesma desenvolva habilidades relacionado à maternagem, assim como o sucesso como esposa e, quando estas expectativas não são atingidas, há muito sofrimento psíquico.

Já no que se refere ao homem, Zanello (2018) propõe que há na sociedade brasileira uma exigência com relação à eficácia laboral e sexual, que são interpretados socialmente como demonstração de virilidade, produtividade e desempenho sexual. Nesse sentido, deve-se atentar ainda o modo como, por vezes, tais expectativas sociais tornam-se estressores psicossociais, o que pode explicar, ainda que parcialmente, a alta taxa suicídio em homens separados, viúvos, desempregados e em idade avançada, ou seja, aqueles que não correspondem às representações sociais relacionado aos papéis masculino nas esferas do trabalho e da sexualidade (BAÉRE; ZANELLO, 2018).

Por sua vez, o suicídio em mulheres, geralmente, é motivado por fatores como abuso sexual e emocional, negligência, assim como dificuldades econômicas (JAWORSKI, 2010). Outro dado importante diz respeito a maior incidência de suicídio em mulheres que moram sozinhas, jovens casadas, especialmente em casos onde o casamento se dá quando a em idade precoce Blumenthal (2010) apud Meneghel et. al (2012).

Já Botega (2015) ao comentar sobre o porquê de haver menor índice de mortalidade por suicídio entre mulheres, destaca que estas possuem melhor adaptação aos papéis sociais que the são requeridos, bem como outros fatores, tais como: o reduzido consumo de álcool, maior taxa de envolvimento religioso. Além destes, é importante destacar o fato de que as mulheres frequentemente pedem mais ajuda, fazem uso com maior 
frequência dos serviços de saúde, recebem maior suporte familiar, bem como, tendem a apresentar habilidades sociais mais desenvolvidas, como a comunicação, o que favorece que discutam seus problemas com maior facilidade, viabilizando assim mais alternativas para solucionar seus problemas (VIJAYAKUMAR, 2015).

Frente o exposto, pode-se dizer que o principal objetivo deste estudo é analisar se a religiosidade é um fator de proteção contra ideação suicida em jovens cristãos, bem como descrever o perfil sócio-demográfico da amostra; compreender o grau de envolvimento religioso da amostra e identificar diferenças significativas de gênero quanto à ideação suicida.

A principal hipótese deste estudo é que a religiosidade pode ser fator de proteção à ideação suicida em jovens cristãos.

\section{METODOLOGIA}

Foi realizada uma pesquisa de campo, de cunho descritivo, apresentando um delineamento de levantamento de natureza quantitativa, a partir da técnica não-probabilística acidental. Participaram desta pesquisa 50 pessoas, de ambos os sexos, tendo como critério de inclusão ter entre 18 e 29 anos e pertencer a alguma denominação cristã, católica ou evangélica/protestante, sendo excluídos aqueles que não estivessem dentro da faixa etária proposta, se declarasse sem religião ou pertencente a outro credo que não fosse cristão.

Para tanto, foram utilizados três instrumentos: (I) Questionário Sócio-demográfico; (II) Escala de Religiosidade Durel e (III) a Escala Multi-Atitudinal de Tendência ao Suicídio.

I. O questionário sóciodemográfico teve como objetivo descrever o perfil da amostra, sendo composto de questões relativas à idade, sexo, estado civil, nível socioeconômico, grau de escolaridade, assim como, qual a filiação religiosa do participante: católica, evangélica, sem religião e outros.

II. A Escala de Religiosidade de Duke (DUREL) foi aplicada visando delinear o perfil religioso da amostra. Esta escala que foi desenvolvida por Koening, Meador e Parkerson (1997), sendo validada para o contexto brasileiro por Moreira-Almeida et. al (2008) e contém 5 itens, que inter-relacionam 3 dimensões da religiosidade, que são: a organizacional (RO), a não-organizacional (RNO) e a intrínseca (RI). Cada dimensão deve ser analisada separadamente, não sendo somadas em um escore total. O 
primeiro e segundo itens são pertencentes às dimensões RO e RNO, respectivamente, e são indicadores de saúde física, mental e de suporte social, variando de 1 (muita religiosidade) a 6 (pouca religiosidade). Os 3 últimos itens são relativos à $\mathrm{RI}$, que devem ser somados para obtenção de um score, que pode variar de 3 (muita religiosidade) a 15 (pouca religiosidade).

III. A Escala Multi-Atitudinal de Tendência ao Suicídio foi utilizada com o intuito de se observar a atitude dos participantes frente ao suicídio. Este instrumento foi desenvolvido por Orbach et. al (1991) e adaptado para o contexto brasileiro por Aquino (2009), sendo composto por 20 questões, com respostas dispostas em uma escala tipo likert, variando de 1 = Discordo totalmente a 5 = Concordo totalmente. Os itens avaliam quatro atitudes básicas frente à vida e a morte: Atração pela vida (AV), Repulsão pela vida (RV), Atração pela morte (AM) e Repulsão pela morte (RM).

Após a aprovação do Comitê de Ética em Pesquisa do Centro Universitário de João Pessoa - UNIPÊ, foram iniciados os procedimentos de coleta de dados. Os instrumentos utilizados foram devidamente adaptados para o sistema de questionários online Google Forms (http://www.google.com/forms/about) e, em seguida, disponibilizados em diversos grupos online, visando-se alcançar o público-alvo da pesquisa.

Ao clicarem no link, os participantes eram encaminhados a uma nova página contendo o Termo de Consentimento Livre e Esclarecido, no qual tomaram conhecimento dos objetivos da pesquisa de maneira clara e resumida, bem como dos possíveis riscos e benefícios que poderiam sofrer ao participar da pesquisa, sendo-lhes assegurado o direito de interromper sua participação na pesquisa a qualquer momento. Além disso, os participantes foram informados pelo termo de consentimento a respeito da possibilidade de publicação dos resultados, garantindo-lhes ainda o anonimato, o sigilo das suas respostas, não sendo exigidas informações a respeito de nome, endereço ou demais documentos ou dados de identificação.

Em seguida, o participante era encaminhado a uma página contendo o Questionário Sócio-demográfico. Após tê-lo respondido, eram abertas as páginas contendo a Escala de Religiosidade Duke e a Escala Multi-Atitudinal de Tendência ao Suicídio, respectivamente.

A análise exploratória dos dados foi realizada por meio de medidas descritivas para os dados sóciodemográficos (médias, desvio-padrão e frequências). A Escala de Religiosidade Duke e a 
Escala Multi-Atitudinal de Tendência ao Suicídio foram analisadas por meio de estatísticas inferenciais, sendo processados pelo programa Statistical Package for the Social Sciences (SPSS), versão 23.0.

Deve-se ressaltar que este estudo foi realizado considerando-se os aspectos éticos pertinentes a pesquisas envolvendo seres humanos, de acordo com a Resolução n 466/12, cumprindo-se as exigências contidas nos termos dos incisos IV-3 e IV-5.

\section{RESULTADOS}

A amostra foi composta por 50 pessoas, sendo a maioria do sexo feminino com $64 \%$ ( $n=32$ ), com uma média de idade de 24 anos (DP 3,0). Com relação à filiação religiosa, houve predominância de evangélicos, 54 \% ( $n=27)$. Quanto ao estado civil, $74 \%(n=37)$ dos participantes declarou-se solteiro. Quanto à renda mensal, $64 \%$ da amostra ( $n=32$ ) recebe entre 1 a 3 salários mínimos, enquanto que $36 \%$ possui nível superior incompleto $(n=18)$, de acordo com a tabela abaixo:

Tabela 1. Caracterização da Amostra

\section{Perfil}

Sexo

Masculino

Feminino

\section{Estado Civil}

Solteiro (a)

Casado (a)

Religião

Católico (a)

23

27

37

74

13

26

Evangélico(a)

\section{Renda}


Até 6 salários mínimos

Até 9 salários mínimos

Mais de 12 salários mínimos
13

4

1
26

8

2

\section{Escolaridade}

Fundamental Incompleto

Médio Incompleto

Médio Completo

Superior Incompleto

Superior Completo

Pós-graduação

Mestrado
2

2

10

18

11

5

2
4

4

20

36

22

10

4

Fonte: Dados obtidos pelo autor

Com relação ao aspecto religioso, os scores obtidos pelas três subescalas da Escala de Religiosidade Duke foram os seguintes: a Religiosidade Organizacional (RO), que mede a frequência aos cultos, obteve um score médio de 2,3 pontos (DP 1,35); a Religiosidade Não-Organizacional (RNO), que verifica a frequência das práticas religiosas individuais, apresentou um score médio de 3 pontos (DP 1,45) e, a religiosidade Intrínseca (RI), que avalia a percepção subjetiva da religiosidade 5,24 (DP 2,17).

Ao se comparar os scores das três dimensões da Escala de Religiosidade Duke entre os grupos católicos e protestantes da amostra, obteve-se os seguintes resultados: o score médio da subescala RO entre católicos foi 2,9 (DP 1,34), entre os evangélicos foi 1,7 (DP 1,15); enquanto que o score médio da subescala RNO entre católicos foi de 3,6 (DP 1,49) e entre os evangélicos 2,4 (DP 1,22). Já o score médio da subescala RNI entre católicos foi de 6,1 (DP 2,21;) e entre evangélicos 4,5 (DP 1,88).

Quanto às diferenças entre sexos, o score médio da subescala RO entre participantes do sexo masculino foi de 1,7 (DP 1,12), entre o feminino 2,6 (DP 1,38). A subescala RNO apresentou, entre participantes do sexo masculino média de 2,3 (DP 1,13) e entre o feminino 3,3 (DP 1,49). Quanto à subescala RI o score médio entre participantes do sexo masculino foi de 5 (DP 2,02) entre o 
feminino 5,3 (DP 2,62). A tabela abaixo detalha os dados acima descritos:

Tabela 2 - Distribuição média dos scores de religiosidade Variáveis

RO

RNO

RI

\begin{tabular}{cccccccc}
\hline Religião & $\mathbf{N}$ & Média & DP & Média & DP & Média & DP \\
Católico & 23 & 2,9 & 1,34 & 3,6 & 1,49 & 6,1 & 2,21 \\
Evangélico & 27 & 1,7 & 1,15 & 2,4 & 1,22 & 4,51 & 1,88 \\
Sexo & & & & & & & \\
Masculino & 18 & 1,7 & 1,12 & 2,3 & 1,13 & 5,0 & 2,02 \\
Feminino & 32 & 2,6 & 1,38 & 3,3 & 1,49 & 5,3 & 2,62 \\
\hline
\end{tabular}

Fonte: Dados obtidos pelo autor

Já no que tange à avaliação da ideação suicida dos participantes, a Escala Multi-Atitudinal de Tendência ao Suicídio, apresentou os seguintes resultados: o fator Repulsão em relação à morte (RM) obteve como média 2,72 (DP 0,25); já o fator Repulsão em relação à vida (RV) 1,84 (DP 0,74); o fator Atração em relação à vida (AV) 4,08 (DP 0,77). Por fim, o fator Atração pela morte (AM) apresentou pontuação média de 2,28 (DP 1,04).

Já quando comparamos os resultados por grupo religioso e gênero, os resultados foram os seguintes, conforme a tabela abaixo:

Tabela 3 - Distribuição média da avalição da ideação suicida

\begin{tabular}{cccccccccc}
\hline Variáveis & \multicolumn{2}{c}{ RM } & \multicolumn{2}{c}{ RV } & \multicolumn{2}{c}{ AV } & \multicolumn{2}{c}{ AM } \\
\hline Religião & Média & DP & Média & DP & Média & DP & Média & DP \\
Católico & 3,13 & 0,32 & 1,85 & 0,75 & 4,33 & 0,09 & 2,36 & 1,41 \\
Evangélico & 2,37 & 0,25 & 1,82 & 0,73 & 4,02 & 0,83 & 2,1 & 0,68 \\
Sexo & & & & & & & & \\
Masculino & 2,33 & 0,19 & 1,8 & 0,55 & 4,25 & 0,05 & 2,05 & 0,47 \\
Feminino & 2,93 & 0,38 & 1,85 & 0,87 & 4,07 & 1,05 & 2,34 & 1,45
\end{tabular}

Fonte: Dados obtidos pelo autor 
Pôde-se então, observar que as maiores médias foram encontradas no fator "Atração em relação à vida" (AV), entre os grupos católico com 4,33 pontos (DP 0,09), assim como entre os participantes do sexo masculino, que pontuaram em média 4,25 (DP 0,05$)$ neste fator. Cabe destacar ainda que os menores scores encontrados foram no fator "Repulsão em relação à vida" (RV), entre os evangélicos, que tiveram média de 1,82 pontos (DP 0,73 ) e entre os participantes do sexo masculino, com 1,8 pontos (DP 0,55 ).

Quando se efetuou uma análise entre as variáveis deste estudo, isto é, entre religiosidade e ideação suicida, percebeu-se algumas correlações bastante significativas, como indica a tabela abaixo:

Tabela 4 - Correlatos de Religiosidade e Ideação Suicida

\begin{tabular}{|c|c|c|c|c|c|c|c|c|}
\hline Variáveis & Média & DP & RO & RNO & $\mathbf{R} \mathbf{I}$ & RM & RV & AV \\
\hline$R O$ & 2,3 & 1,35 & - & - & - & - & - & - \\
\hline RNO & 3 & 1,45 &, $577^{* *}$ & - & - & - & - & - \\
\hline$R I$ & 5,24 & 2,17 &, $487^{* *}$ &, $445^{* *}$ & - & - & - & - \\
\hline$R M$ & 2,72 & ,972 & 274 & ,245 & 192 & - & - & - \\
\hline$R V$ & 1,84 & ,636 & ,057 & 123 &, $327^{*}$ & ,066 & - & - \\
\hline$A V$ & 4,08 &, 530 &,- 151 &,- 211 &,$- 515^{* *}$ & ,013 &,$- 541^{* *}$ & - \\
\hline$A M$ & 2,23 & 673 &, $365^{* *}$ &, $358^{*}$ &, $347^{*}$ & 125 &, $471^{* *}$ &,- 277 \\
\hline
\end{tabular}

Fonte: Dados obtidos pelo autor

Notas: ${ }^{*} p<0,05, * * p<0,01$

Verificou-se, então, que tanto a religiosidade organizacional (RO) quanto a não-organizacional (RNO) tiveram uma correlação positiva fraca com atração pela morte (AM), sendo a segunda muito significativa $(p<0,01)$. Já a religiosidade intrínseca (RI) apresentou uma correlação fraca, mas significativa $(p<0,05)$ com repulsão pela vida (RV) e atração pela morte (AM), bem como uma correlação negativa moderada, muito significativa $(p<0,01)$, com atração pela vida (AV). Cabe ressaltar ainda que não foram encontradas nenhuma correlação significativa do fator Repulsão pela Morte (RM) com nenhuma das dimensões de religiosidade avaliadas. 


\section{DISCUSSÃO}

Ao analisarmos os resultados obtidos pela Escala de Religiosidade Duke, observou-se que a amostra possui um elevado grau de religiosidade nas três dimensões (RO, RNO, RI), o que coaduna com um levantamento realizado em 143 cidades brasileiras, que concluiu que a população brasileira possui um alto nível de envolvimento religioso, com elevada frequência a cultos (MOREIRA-ALMEIDA et. al, 2010). Entretanto, cabe ressaltar que as maiores pontuações foram encontradas nos participantes do sexo masculino, o que difere de alguns estudos que mostram que as mulheres possuem maior envolvimento religioso que homens (CRES et. al. 2015; GONÇALVES et. al 2017; KREGTING, 2019; SCHNABEL, HACKETT e MCCLENDON, 2018).

O nível de religiosidade apresentado pela amostra pode ser um indicador positivo, pois conforme Koening e Büssing (2010) destacam, a dimensão organizacional da religiosidade tem sido associada a menores índices de depressão, maior suporte social, melhor saúde física, baixo uso do serviço de saúde e menor taxa de mortalidade.

Além disso, estudos mostram uma correlação positiva entre a religiosidade não-organizacional e práticas de alimentação mais saudável, assim como uma significativa diminuição da ansiedade (CRES et. al, 2015; GONÇALVES et. al, 2017). Já o estudo realizado por Mosqueiro (2015) demonstrou que há uma correlação entre a dimensão da religiosidade intrínseca e menos tentativas de suicídio.

Muito embora a Escala Multi-Atitudinal de Tendência ao Suicídio não apresente um score geral, pode-se dizer que as médias entre encontradas nesta amostra, nos quatro fatores, situaram-se dentro dos parâmetros de normalidade, de acordo com os índices encontrados por Orbach et. al (1991), que comparou adolescentes, que foram classificados em três grupos: "suicida", "psiquiátrico" e "normal".

Também se verificou que tanto homens quanto mulheres tiveram médias dentro padrão de normalidade com relação à ideação suicida, indicando que não há risco potencial de suicídio. Resultados semelhantes foram encontrados por VasconcelosRaposo et. al. (2016), em uma amostra de estudantes universitários, que não encontrou nenhuma diferença estatisticamente significativa entre os sexos quanto à ideação suicida. 
Quanto as análises correlacionais, destaca-se os resultados encontrados no fator Atração pela Morte, que conforme Aquino (2009) observa, está relacionado a crenças de que a morte pode ser um estado superior e desejável, repleto de paz e tranquilidade.

Em estudo feito com adolescentes, Orbach et. al (1991) verificaram uma correlação positiva $(r=0,48, p<0,05)$ entre a possibilidade de uma pessoa cometer suicídio e a atração pela morte. Já no presente estudo observou-se que este fator obteve correlações positivas, fracas com as três dimensões da religiosidade, diferindo do estudo de Santos et. al (2016) que observaram uma correlação negativa fraca entre atração pela morte e compromisso religioso.

Uma explicação alternativa para este resultado é a crença cristã no pós-morte como sendo um lugar de repouso para os fiéis e, tal como observa Kralovec et. al (2017) os benefícios protetivos da religião estão ligados também à forma como a pessoa se relaciona com suas crenças religiosas. Jongkind et. al (2018) em um estudo com pacientes depressivos cristãos verificou que o tipo de representação de Deus que o sujeito possua pode associar-se positiva ou negativamente com ideação suicida.

Merece destaque ainda a análise de Minois (1998) citado por Aquino (2009), que concebe a fé cristã como o equilíbrio entre o desejo de morrer e, ao mesmo tempo, suportar a vida. Esta busca é expressa nas palavras de S. Paulo, quando escreve aos Filipenses (1.23-24): "Estou pressionado dos dois lados: desejo partir e estar com Cristo, o que é muito melhor; contudo, é mais necessário, por causa de vocês, que eu permaneça no corpo (BÍBLIA, 2008).

\section{CONSIDERAÇÕES FINAIS}

Ao fim deste estudo reconhece-se que o espectro do comportamento suicida, principalmente, a ideação suicida é multideterminado e sua relação com a religiosidade ainda é ambivalente, de modo que esta pode tanto se associar a características frequentemente tidas como protetivas, quanto de risco.

Foi possível verificar que a amostra apresenta um alto grau de envolvimento religioso, bem como níveis normais de ideação suicida. No entanto, vale destacar que as três dimensões da religiosidade se correlacionaram de modo significativo com o 
fator Atração pela Morte, o que pode ser explicado a partir da ideia cristã de que a morte não é, necessariamente, a aniquilação da vida, mas um estado de descanso dos sofrimentos próprios da condição humana.

Ainda vale ressaltar que este estudo também possui algumas limitações, tais como o tamanho da amostra, sendo, então, necessária a realização de uma pesquisa mais abrangente, com uma amostra representativa da população, para que seja possível uma generalização dos resultados. Sugere-se ainda a realização de um estudo qualitativo, que busque compreender mais profundamente quais crenças religiosas do cristianismo tem um potencial protetivo ou de risco em relação à ideação suicida.

Além disso, é válido salientar que a Escala de Religiosidade Duke, embora seja um instrumento sucinto e de fácil aplicação, não possui um score total, não sendo assim possível obter um índice único de religiosidade da amostra, o que pode ser um dos fatores responsáveis por algumas das discrepâncias encontradas entre este estudo e outros encontrados na literatura.

\section{REFERÊNCIAS}

ABREU, K. P. et. al. Comportamento suicida: fatores de risco e intervenções preventivas. Revista Eletrônica de Enfermagem. 2010. v.12 n.1, p.195-200. Disponível em: http://fen.ufg.br/revista/v12/n1/pdf/v12n1a24.pdf. Acesso em 13 de maio de 2019.

AQUINO, T. A. A. de. Atitudes e intenções de cometer o suicídio: seus correlatos existenciais e normativos. 2009. 280f. Tese (Doutorado em Psicologia Social) - Programa Integrado de Doutorado em Psicologia Social, Universidade Federal da Paraíba e Universidade Federal do Rio Grande do Norte, João Pessoa, 2009. Disponível em: http:://docplayer.com.br/27331964-Atitudes-eintencoes-de-cometer-o-suicidio-seus-correlatos-existenciais-enormativos.html. Acessado em: 15 ago. 2019. 
ASANTE, K. O. et. al. The prevalence and correlates of suicidal behaviours (ideation, plan and attempt) among adolescents in senior high schools in Ghana. SSM-Population Health, v. 3, p. 427434, $2017 . \quad$ Disponível em: https://www.sciencedirect.com/science/article/pii/S235282731730 0320 . Acesso em: 10 mar. 2019.

BAERE, F. ZANELLO, V. O gênero no comportamento suicida: Uma leitura epidemiológica dos dados do Distrito Federal. Estudos de Psicologia, Natal, v. 23, n. 2, p. 168-178, jun. 2018. Disponível em http://pepsic.bvsalud.org/scielo.php?script=sci_arttext\&pid=S1413 294X2018000200008\&Ing=pt\&nrm=iso. Acesso em: 13 maio 2019.

BECKER, S.O. WOESSMANN, L. Knocking on Heaven's Door? Protestantism and Suicide. The University of Warwick: Department of Economics, v. 12, n 33, p. 3-28. Jun. 2011. Disponível em: http://wrap.warwick.ac.uk/41111/1/WRAP_Becker_twerp_966.pdf .Acessado em: 28 fev. 2019.

BÍBLIA de Estudo NVI. Nova Versão Internacional. Português. São Paulo, SP: Vida, 2003.

BOTEGA, N. J. Comportamento suicida: epidemiologia. Psicologia USP, São Paulo, v. 25, n. 3, p. 231-236, dez. 2014. Disponível em: http://www.scielo.br/scielo.php?script=sci_arttext\&pid=S01036564 2014000300231\&Ing=pt\&nrm=iso. Acesso: 30 mar. 2019.

BOTEGA, N. J. Crise Suicida: avaliação e manejo. Porto Alegre: Artmed, 2015.

BRAGA, L. L.; DELL'AGLIO, D. D. Suicídio na adolescência: fatores de risco, depressão e gênero. Contextos Clínicos. Revista online. vol.6, n.1, pp. 2-14, 2013. Disponível em: http://pepsic.bvsalud.org/scielo.php?script=sci_arttext\&pid=S1983 34822013000100002\&lng=pt\&nrm=iso. Acesso em: 05 mar. 2019.

BRASIL. Ministério da Saúde. Agência de Saúde, Notícia. Brasília, 2018.Disponível em:

http://portalms.saude.gov.br/noticias/agencia-saude/44404novos-dados-reforcam-a-importancia-da-prevencao-do-suicidio. Acesso: 03 mar. 2019. 
BRASIL. Ministério da Saúde. Secretaria de Vigilância em Saúde. Boletim Epidemiológico, Brasília, v. 48, n. 30. 2017. Disponível em: http://portalarquivos2.saude.gov.br/images/pdf/2017/setembro/2 1/2017-025-Perfil-epidemiologico-das-tentativas-e-obitos-porsuicidio-no-Brasil-e-a-rede-de-atencao-a-saude.pdf. Acesso em: 20 fev. 2019.

CHEN, Y. et. Al. Female labour force participation and suicide rates in the world. Social Science \& Medicine. [s.l.] v.195, p. 61-67, dez. 2017. Disponível em: https://www.sciencedirect.com/science/article/pii/S027795361730 6780. Acesso em: 17 mar. 2019.

CRES, M. R. et. al. Religiosidade e estilo de vida de uma população adulta. Revista Brasileira de Promoção à Saúde, Fortaleza, v. 8, n.22, p. 40-250, abr./jun., 2015.

DURKHEIM, E. O suicídio: estudo de sociologia. Traducão de Mônica Stahel. São Paulo: Martins Fontes, 2000.

FREEMAN, A. et. al. A cross-national study on gender differences in suicide intente. BMC Psychiatry, [s.I.] v. 17, n. 234, p. 1-11, 2017. Disponível em: https://www.ncbi.nlm.nih.gov/pmc/articles/PMC5492308/. Acesso em: 14 mar. 2019.

FREITAS, S. A. P. Variáveis preditoras da ideação suicida em alcoólicos e deprimidos. 2011. 73 f. Dissertação (Mestrado) Curso de Psicologia, Faculdade de Ciências Humanas e Sociais, Universidade do Algarve, Faro, Portugal, 2011. Disponível em: https://sapientia.ualg.pt/bitstream/10400.1/3152/1/Tese\%20Vers \%C3\%A30\%20Final\%20impressa_silvana.pdf. Acesso em: 20 fev. 2019.

GONÇALVES, J. S. et. al. Religiosidade e os Transtornos Mentais comuns em Adultos. Revista enfermagem. UFPE on line; v.11 n. 4, p. 1708-1715, abr. 2017. Disponível em: https://periodicos.ufpe.br/revistas/revistaenfermagem. Acessado em: 12 out. 2019. 
HSIEH, N. A Global Perspective on Religious Participation and Suicide. Journal Of Health And Social Behavior, [s.l.], v. 58, n. 3, p.322-339, 22 jun. 2017. SAGE Publications. Disponível em http://dx.doi.org/10.1177/0022146517715896. Acesso em: 14 maio 2019.

JAWORSKI, K. The Gender-ing of Suicide. Australian Feminist Studies, v. 25, n. 63, mar. 2010. Disponível em: https://www.researchgate.net/publication/233270814_The_gende r-ing_of_suicide. Acesso em: 16 maio 2019.

JONGKIND, M. et. al. Dimensions of Religion Associated with Suicide Attempt and Suicide Ideation in Depressed, Religiously Affiliated Patients. Suicide and Life-Threatening Behavior. [s.l.], p.1-15, 20 abr. 2018. Disponível em: https://onlinelibrary.wiley.com/doi/epdf/10.1111/sltb.12456. Acesso em: 20 fev. 2019.

KOENIG, H.G.; BÜSSING, A. The Duke University Religion Index (DUREL): A Five-Item Measure for Use in Epidemological Studies. Religions, [s.I.], v. 1, n. 1, p.78-85, 1 dez. 2010. Disponível em: https://doi.org/10.3390/rel1010078 Acesso em: 18 set. 2019.

KOENING, H. G.; MEADOR, K. G.; PARKERSON, G. Religion index for psychiatric research. American Journal of Psychiatry, [s.I.], v. 154, n. 6, p.885-886, jun. 1997. American Psychiatric Association Publishing. Disponível em :http://dx.doi.org/10.1176/ajp.154.6.885b. Acesso: 21 fev. 2019.

KRALOVEC, K. et. al. The Gender-Specific Associations Between Religion/Spirituality and Suicide Risk in a Sample of Austrian Psychiatric Inpatients. Suicide And Life-threatening Behavior, [s.l.], v. 48, n. 3, p.281-293, 31 mar. 2017. Disponível em: https://onlinelibrary.wiley.com/doi/epdf/10.1111/sltb.12349. Acesso em: 20 de fev. 2019.

KREGTING, J. et al. Why Dutch Women are Still More Religious than Dutch Men: Explaining the Persistent Religious Gender Gap in the Netherlands Using a Multifactorial Approach. Review Of Religious Research, [s.l.], v. 61, n. 2, p.81-108, 28 jan. 2019. Disponível em: https://link.springer.com/content/pdf/10.1007\%2Fs13644-01900364-3.pdf. Acesso em: 12 out. 2019. 
MENEGHEL, S. N. et al. Suicídio de idosos sob a perspectiva de gênero. Ciência e saúde coletiva, Rio de Janeiro, v. 17, n. 8, p. 1983-1992, 2012.

Disponível em: http://www.scielo.br/scielo.php?script=sci_arttext\&pid=S14138123 2012000800009\&Ing=en\&nrm=iso. Acesso em: 3 jun. 2019.

MOREIRA-ALMEIDA, A. et al. Envolvimento religioso e fatores sóciodemográficos: resultados de um levantamento nacional no Brasil. Revista de psiquiatria clínica, São Paulo, v. 37, n. 1, p. 1215, jan. 2010. Disponível em: http://www.scielo.br/scielo.php?script=sci_arttext\&pid=S01016083 $2010000100003 \&$ Ing=en\&nrm=iso. Acesso em: 12 out. 2019.

MOREIRA-ALMEIDA, A. et al. Versão em português da Escala de Religiosidade da Duke: DUREL. Revista de Psiquiatria Clínica, São Paulo, v. 35, n. 1, p. 31-32, 2008. Disponível em:http://www.scielo.br/scielo.php?script=sci_arttext\&pid=S01016 0832008000100006\&lng=en\&nrm=iso. Acesso em: 5 maio 2019

MOREIRA-ALMEIDA, A.; LOTUFO NETO, F.; KOENIG, H. G. Religiousness and mental health: a review. Revista Brasileira de Psiquiatria. São Paulo, v. 28, n. 3, p. 242-250, set. 2006. Disponível em: http://www.scielo.br/scielo.php?script=sci_arttext\&pid=S151644462006000300018\&lng=en\&nrm=iso. Acesso em: 30 mar. 2019.

MOSQUEIRO, B. P. Religiosidade, resiliência e depressão em pacientes internados. 2015. 111 f. Dissertação (Mestrado) Programa de Pós-Graduação em Ciências Médicas: Psiquiatria, Universidade Federal do Rio Grande do Sul, Porto Alegre, 2015.

MOSTAFAZEDH-BORA, M.; ZARGAMIN, A. Vital role of cultural and religious context on suicidal behavior. Psychiatry and Clinical Neurosciences. v. 70, n, 12. p. 582-583, dez. 2016. Disponível em: https://onlinelibrary.wiley.com/doi/full/10.1111/pcn.12458. Acesso em: 29 mar. 2019.

ORBACH, I. et al. A Multi-Attitude Suicide Tendency Scale for Adolescents. A Journal of Consulting and Clinical Psychology. $v$. 3, n. 3, p. 398-404, 1991. Disponível em: http://psycnet.apa.org/buy/1992-03898-001. Acesso em: 23 ago. 2019. 
PÁDUA, E. M. M. Metodologia de Pesquisa: abordagem teóricoprática. $18^{\mathrm{a}}$ ed. Campinas: Papirus, 2017.

RIBEIRO, J. M.; MOREIRA, M. R. An approach to suicide among adolescents and youth in Brazil. Ciência e saúde coletiva, Rio de Janeiro, v. 23, n. 9, p. 2821-2834, set. 2018. Disponível em: http://www.scielo.br/scielo.php?script=sci_arttext\&pid=S141381232018000902821\&lng=en\&nrm=iso. Acesso em: 17 mar. 2019.

SANTOS, J. C. Prevenção do suicídio: Uma tarefa de todos! Revista Portuguesa de Enfermagem de Saúde Mental, Porto, n. 19, p. 67, jun. $2018 . \quad$ Disponível em: http://www.scielo.mec.pt/scielo.php?script=sci_arttext\&pid=S1647 $21602018000100001 \&$ Ing=pt\&nrm=iso. Acesso em: 17 abr. 2019.

SANTOS, W. S. dos et al. The influence of risk or protective factors for suicide ideation. Psicologia Saúde \& Doenças, Lisboa, v. 17, n. 3, p. 515-526, dez. 2016.Disponível em:http://www.scielo.mec.pt/scielo.php?script=sci_arttext\&pid=S1 $64500862016000300016 \&$ Ing=pt\&nrm=iso $>$. Acesso em: 28 mar. 2019.

SCHNABEL, L.; HACKETT, C.; MCCLENDON, D. Where Men Appear More Religious Than Women: Turning a Gender Lens on Religion in Israel. Journal For The Scientific Study Of Religion, [s.I.], v. 57, n. 1, p.80-94, mar. 2018. Disponível em: https://onlinelibrary.wiley.com/doi/full/10.1111/jssr.12498 Acesso em: 12 out. 2019.

SPENCER-THOMAS, S. Flaming Chalice of Hope: A Case Study of Suicide Prevention in a Faith Community. Religions, [s.l.], v. 9, n. 4, p.123-167, 11 abr. 2018. MDPI AG. Disponível em: http://dx.doi.org/10.3390/rel9040123. Acesso em: 29 mar. 2019.

STACK, S. Religious Activities and Suicide Prevention: A Gender Specific Analysis. Religions, [s.I.], v. 9, n. 4, p.127-139, 13 abr. 2018. MDPI AG. Disponível em: http://dx.doi.org/10.3390/rel9040127. Acesso em: 18 fev. 2019. 
VASCONCELOS-RAPOSO, J. et al. Níveis de ideação suicida em jovens adultos. Estudos de Psicologia Campinas, v. 33, n. 2, p. 345-354, jun. 2016. Disponível em: http://www.scielo.br/scielo.php?script=sci_arttext\&pid=S0103166X 2016000200345\&lng=pt\&nrm=iso. Acesso em: 05 mar. 2019.

VIJAYAKUMAR, L. Suicide in women. Indian Journal of Psychiatry. 2015. Jul. v. 57 n. 2. S233-S238. Disponível em: https://www.ncbi.nlm.nih.gov/pmc/articles/PMC4539867/?report= classic Acesso em: 16 mar. 2019.

WORLD HEALTH ORGANIZATION, (WHO). Mental Health, Suicide. Geneva, 2018. Disponível em: https://www.who.int/mental_health/prevention/suicide/suicidepre vent/en/ Acesso: 20 de fev. 2019.

WORLD HEALTH ORGANIZATION, (WHO). Preventing Suicide: a global imperative. Geneva, 2014.

ZANELLO, V. Saúde mental, gênero e dispositivos: cultura e processos de subjetivação. Curitiba: Appris, 2018. 